expand, but fragments) is also discussed, with the conclusion that present evidence does not support very large-scale expansion. N. W. Radforth then considers disagreement has been the rule. Some important new evidence from the Canadian Arctic is briefly mentioned, and emphasis on functional and adaptive morphology of plants rather than routine palaeo-floristic studics is emphasized. R. W. Tanner gives a valuable short sum. mary of the possibility of measuring rates of drift by means of astronomical observations of latitude and longitude. After eliminating as far as possible the instrumental and other sources of error, it is shown that latitude determinations appear to exclude $\mathrm{N}-\mathrm{S}$ movements greater than about $1 \mathrm{~cm} / \mathrm{yr}$ at present, but that longitude differences have been subject to instrumental inaccuracies and most of them have not been able to exclude a relative movement up to $0.5 \mathrm{~m} / \mathrm{yr}$. The use of flashing satellites, with numerous stations and recording to m.sec accuracy or better, might well give information over a fow decades of systermatic change of the order of $1 \mathrm{~cm} / \mathrm{yr}$; this is the order required to satisfy most theories of drift, as noted earlier by Deutsch.

The second section provides a wealth of bathymetric and geophysical information, much of it new, for the Canadian Arctic (B. R. Pelletier), the Nova Scotian Shelf (by J. Berger, A. E. Cok, J. E. Blanchard and M. J. Keen), and the Gulf of the St. Lawrence (by A. K. Goodacre and E. Nyland). Finally, H. L. Cameron considers the Cabot fault zone of Newfoundland and the Maritimes; this zone is of interest because J. T. Wilson has suggested that the Cabot fault may be a continuation of the Great Glen fault of Scotland. Using air-photographs, aeromagnetic survey maps and bathymetric maps with groundcontrol, he suggests that the faults are probably "highangle thrusts" with only small horizontal movement, There is much useful material, but some of the weight of the conclusions is lessened when it is accepted as possible that faults with lateral shift may run along the trend of fold-structures and not necessarily, as classical wrenchfaults do, across them.

This is a well produced book in which I noted only a few typographical errors. It should find a place in the library of those interested in continental drift, and those concerned with the morphology of eastern and northern Canada.

T. S. WESTOLL the palaeobotanical evidence; this is a field in which violent beginning in Devonian ( ?) or possibly earlier times.

hydrograph analysis is dismissed in less than one page, with no diagrams, in favour of a method based on ante. cedent precipitation which is not properly described; Horton's classic work on the role of infiltration in streamflow is mentioned only once no reference is givenand in the concluding paragraph of the chapter on highwater runoff the author suggests, in typically tautological fashion, that: "An important factor frequently overlooked in theoretical and practical investigations of runoff and discharge is the reduction of infiltration with time" ! The reader conversant with English and American hydrology will find other equally significant omissicns; thus Sherman's work on the unitgraph is mentioned, although no reference is given, while in the field of evapotranspiration the names of Dalton and Meyer appear, but nowhere is there a mention of Thornthwaite or Penman.

Russian parochialism is further evidenced by the author's frequent statements, in apparently general terms, of what, in fact, applies only to Russian conditions; by the dearth of non-Russian references, and by peculiarities of terminology. All of this is surpassed by a single paragraph on page four in which the author not only lists a number of Russian and Soviet hydrologists as among "the founders of hydrology", but also notes that "... Soviet hydrology has firmly acquired the status of a science, whereas in foreign countries, particularly in the U.S.A., hydrology has not yet overcome the empirical stage"!

Deficiencies in presentation seem to be the responsibility partly of the author, for example, unlabelled résumes at the ends of chapters, no list of illustrations, poor quality of line drewing and frequent ambiguities in the maps and diagrams, and fragmentation of discussion on particular topics among several chapters. The translator is partly to blame, too, for example, for numerous typographical orrors; diagrams frequently located away from the relevant text; stilted translation resulting in phrases such as "calendaristic dates" and "calendaristic seasons" and, most important of all, the absence of an index, which adds further to the reader's problems.

Despite its shortcomings the book contains a large body of hitherto unknown experimental data, some of which, for example those relating to snowmelt contributions to streamflow, will be of general interest, and in addition, clearly illustrates many of the applications of statistical techniques in hydrological problems. If only for these reasons it will be read with considerable interest.

R. C. WARD

\section{HYDROLOGY IN RUSSIA}

\section{Theory of Stream Runoff}

By N. P. Chebotarev. Translated from the Russian by Adolf Wald. Edited by M. Diskin. Pp. v+464. (Jerusalem: Israel Program for Scientific Translations; London : Oldbourne Press, 1966.) $108 s$.

THIs translation provides a valuable insight on Russian hydrology before the mid-1950s and it is presumably as a historical document that it has been published. Certainly its hydrological content verges on the antediluvian in terms both of the age of the data presented (almost onethird of the listed references bear a pre-1954 date, while only 2 per cont-seven references-are dated after 1955), and also of the empirical nature of the argument which is reminiscent of much American hydrological literature in the $1930 \mathrm{~s}$ and $1940 \mathrm{~s}$.

Both in the title and in the early paragraphs the reader may be mistakenly led to believe that the emphasis will be on hydrological theory. Instead the author's reliance on empirical and statistical relationships, frequently in the form of simple linear regressions between complex hydrological variables, is emphasized by somo rathor fundamental omissions. Thus, the determination of the groundwater component of total atreamflow by means of

\section{VOLCANOES OF THE SOUTH SEAS}

Geology of the State of Hawaii

By Harold T. Stearns. Pp. xxii $+266+12$ plates. (Palo Alto, California: Pacific Books, 1966.) $\$ 8.50$.

Harold Stearns is a field geologist par excellence, and this is apparent in his new book on the geology of Hawaii. Drawing together his previous work he has produced a book which is charming, easy to read and well presented. The text leans heavily on the field side of the subject, that is, geomorphology and general geology, and Stearns's treatment of volcanic landforms is authoritative to the point of being classic. Almost every term used in the book is defined, so that the text will doubtless become an established text for young students as well as appealing to the general reader.

Having given praise where praise is due it must bo said that, although the petrology of the Hawaiian lavas is a classic part of geologic lore one would not guess it from reading this book-the petrology, geochemistry and geophysics are dealt with quite inadequately in a chapter at the end of the book. No indication is given of the tremendous problem of the origin of magmas and the 